\title{
Facilitation, interference, and scale: the spatial distribution of prey patches affects predation rates in an estuarine benthic community
}

\author{
Anson H. Hines ${ }^{1, *}$, W. Christopher Long ${ }^{1}$, Jeffrey R. Terwin ${ }^{1,2}$, Simon F. Thrush ${ }^{3}$ \\ ${ }^{1}$ Smithsonian Environmental Research Center, 617 Contees Wharf Road, Edgewater, Maryland 21037, USA \\ ${ }^{2}$ North Shore Country Day School, 310 Green Bay Road, Winnetka, Illinois 60093, USA \\ ${ }^{3}$ National Institute of Water and Atmospheric Research, PO Box 11-115, Hamilton, New Zealand
}

\begin{abstract}
The interaction of prey distribution patterns and predator behavior can mediate predator-prey dynamics. Inter-patch distance (lag) may be especially important in the interacting effects of aggregation and interference among predators on their search and prey-handling ability. Interactions of blue crabs Callinectes sapidus preying upon thin-shelled clams Macoma balthica in Chesapeake Bay provide a test of how the opposing forces of aggregation and interference interact with the spatial distribution of prey patches to influence rates of prey consumption. Blue crabs can detect clam patches from up to $15 \mathrm{~m}$ away using chemosensory cues, and they aggregate on them, thus facilitating predation, but exhibit agonistic behaviors when closer than $5 \mathrm{~m}$ to another crab, thus reducing feeding efficiency. We used these patterns of aggregation and interference to modify a generalized functional response model to describe individual crab foraging efficiency as a function of distance between patches. The model predicted highest predation rates at an intermediate lag of $6.6 \mathrm{~m}$. We tested this a priori hypothesis with a set of field experiments wherein prey patches were established with lags of $1,7,10$, and $50 \mathrm{~m}$. Predation rates were highest at intermediate lags, as predicted. This work highlights the importance of the interaction between spatial scales and ecological processes, demonstrating that spatial heterogeneity is not noise that obscures processes, but an active component of the predator-prey dynamic.
\end{abstract}

KEY WORDS: Lag · Aggregation · Interference $\cdot$ Clams $\cdot$ Blue crabs · Predator-prey interaction Spatial ecology

- Resale or republication not permitted without written consent of the publisher

\section{INTRODUCTION}

\section{Spatial dynamics in predator-prey interactions}

Predator-prey dynamics can be mediated by the interaction of prey distribution patterns and predator behavior and mobility (Schwinning \& Rosenweig 1990, Schneider 1992, Hines et al. 1997). Predation can restrict the distribution and abundance of prey and affect overall community structure (Krebs 1985) in both terrestrial (Wiens 1989) and aquatic (Hines et al. 1990, Thrush et al. 1994) systems. Conversely, a predator's success in feeding on patchily distributed prey de- pends on both its ability to locate patches of prey and its ability to select, capture, and consume prey within a patch (Schneider 1978, 1982, 1992, Cummings et al. 1997).

Some predators respond to variations in prey density through an aggregative response to maximize foraging efficiency (Hassell 1978); mites (Nachman 2006), rays (Hines et al. 1997), wading birds (Goss-Custard 1980), and crabs (Clark et al. 1999b) all demonstrate an aggregative response that facilitates foraging. Some predators benefit by foraging in larger groups, leading to predator aggregation in high-density prey areas (Master et al. 1993), or use foraging cues from other 
predators to locate and aggregate on prey patches (Weissburg \& Zimmer-Faust 1991, Zimmer-Faust et al. 1999).

However, aggregation can also reduce a predator's foraging efficiency, as interference between predators reduces the time and energy available for foraging (Ens \& Goss-Custard 1984, Smith \& Taylor 1993, Clark et al. 1999a,b). Interference includes behaviors such as agonistic threat, predator displacement, and predator fighting (e.g. Smallegange et al. 2006), and results in a decrease in foraging efficiency with increasing predator density (Mansour \& Lipcius 1991, Clark et al. 1999a).

Thus, the spatial arrangement of prey results in 2 opposing factors influencing the predator-prey dynamics: facilitation and interference. For many predators these processes are likely to operate over different spatial scales. Although the interaction between predator aggregation and interference is well understood (Hassell 1978, Turchin \& Kareiva 1989), its effect on predation rates in the context of heterogeneous prey distribution is not (Vahl et al. 2007). The importance of prey spatial distributions will be crucial where the mechanisms driving predator aggregation and predator interference operate at different spatial scales.

The spatial scale is composed of 3 aspects: (1) grain, the area of a patch; (2) lag, the distance between patches; and (3) extent, the total area encompassed by the study (see Wiens 1989, Thrush et al. 1997a). Multiscale approaches in predator-prey research have focused mainly on the estimate of the grain over which aggregative responses occur, and the extent over which predators affect prey. The influence of lag has received little attention in the literature, even though patchy distributions of prey imply that predators must travel between patches (Nachman 2006).

Distance among prey patches may be especially important for the interacting effects of predator aggregation and interference. Predators may aggregate on prey patches at one scale, yet interact with other predators at a different scale. Oyster-catchers Haematopus ostralegus, for example, aggregate on patches over large scales $(\mathrm{km})$, yet interference between foraging birds occurs over small scales $(<1 \mathrm{~m}$; Ens \& GossCustard 1984). In one of the few experiments to vary lag, interference among turnstones Anenaria interpres, another shorebird, decreased sharply when the lag was greater than the predator size (Vahl et al. 2007). Predator efficiency (or prey mortality) may vary with lag due to differences in aggregation strength and interference intensity over a range of inter-patch distances.

In the present paper, we modify a general functional response model to account for predator aggregation and interference as a function of lag. We test the model's predictions by experimentally manipulating lag in prey patches of clams Macoma balthica fed upon by blue crabs Callinectes sapidus.

\section{Blue crab/clam system of Chesapeake Bay}

In the mesohaline portion of Chesapeake Bay, blue crabs Callinectes sapidus are the dominant predators on the benthic macrofauna, and their diet is composed primarily of bivalves (Hines et al. 1990). The tellinid clam Macoma balthica is the biomass dominant in the system, and comprises up to $55 \%$ of the blue crab diet (Hines et al. 1990). Blue crabs aggregate on highdensity patches of $M$. balthica (Clark et al. 1999a) using odor plumes from actively pumping clams or clam exudates caused by predation by other crabs (Weissberg \& Zimmer-Faust 1993). Blue crabs use chemosensory cues to detect clam patches at a distance of up to 10-15 m (Clark et al. 1999a). Although other predators in the system may nip $M$. balthica siphons or prey on juvenile clams, the blue crab is the only predator to feed on whole adult clams (Hines et al. 1990).

Blue crabs are cannibalistic and exhibit strong agonistic behaviors that reduce feeding efficiency (Mansour \& Lipcius 1991, Smith 1995, Clark et al. 1999b). Adult crabs exhibit threat displays, such as a 'meral spread,' when in the presence of other adult crabs (Jachowski 1974), and fighting between crabs can lead to injury or death (Mansour \& Lipcius 1991). In the field, crabs detect and respond to the presence of other adults at distances of up to 4-5 m (Clark et al. 1999b). Interference among foraging crabs decreases feeding efficiency by up to $80 \%$, due to increased non-feeding interactions with other crabs (Mansour \& Lipcius 1991, Clark et al. 1999a, 2000).

\section{MATERIALS AND METHODS}

The lag model. Functional response models describe the per capita foraging rate of a predator as a function of prey densities (Holling 1959, Hassell 1978). We start with a Holling Type II functional response (Holling 1959):

$$
E=\frac{C N}{1+C H N}
$$

where $E$ is the per capita prey consumption, $N$ is the prey density, $C$ is the capture rate, and $H$ is the handling time.

This model applies to the dynamics of a predator feeding within a patch. To apply the function to a system with discrete prey patches, we define $C$ as the product of $C_{\mathrm{w}}$, the capture rate within a patch, and 
$C_{\mathrm{b}}$ (between patches), as the probability of patch discovery:

$$
E=\frac{C_{\mathrm{b}} C_{\mathrm{w}} N}{1+C_{\mathrm{b}} C_{\mathrm{w}} H N}
$$

Both $C_{\mathrm{b}}$ and $H$ are defined as functions of lag. The ability of a predator to locate patches $\left(C_{\mathrm{b}}\right)$ decreases with increased lag, as predators are better able to aggregate on closer patches. Interference among predators also decreases with lag, and an increase in interference will increase the handling time. Within this modeling framework, changes in $C_{\mathrm{b}}$ have a larger impact than changes in $H$ because $C_{\mathrm{b}}$ is independent of $H$ (i.e. a predator can locate a patch regardless of handling time), but $H$ is dependent on $C_{\mathrm{b}}$ (i.e. to incur handling time the predator must first locate a patch). $C_{\mathrm{b}}$ ranges from 1 , where a predator always discovers a patch, to 0 , where a predator never discovers a patch. Likewise, $H$ ranges from 1 , meaning it takes the entire time available to eat 1 prey item, to 0 , meaning prey consumption is instantaneous. A predator benefits by having a high value of $C_{\mathrm{b}}$ and a low value of $H$. We model $C_{\mathrm{b}}$ and $H$ as exponential decay functions:

$$
\begin{aligned}
& C_{\mathrm{b}}=\left(1-C_{\text {min }}\right) \mathrm{e}^{-r_{C} L}+C_{\text {min }} \\
& H=\left(1-H_{\text {min }}\right) \mathrm{e}^{-r_{H} L}+H_{\text {min }}
\end{aligned}
$$

where $L$ is the $\operatorname{lag}, r_{C}$ is the rate constant for patch detection $\left(C_{\mathrm{b}}\right)$, and $r_{H}$ is the rate constant for handling time. The decay functions both have lower asymptotes $>0$. The lower limit for $C_{\mathrm{b}}, C_{\min }$ is the probability of predators discovering a prey patch in the absence of cues from aggregation (i.e. from other predators). The lower limit of $H_{1} H_{\text {min }}$ is the handling time in the absence of interference. The magnitudes of $r_{C}$ and $r_{H}$ determine the effect of lag on predation rates. Changes in $r_{C}$ and $r_{H}$ lead to different predicted responses in aggregation and interference across lag distances. Exponential decay is appropriate because the rates of change in parameters related to lag are likely to be nonlinear (Hassell 1978). Although both interference (Skalski \& Gilliam 2001) and facilitation (Nilsson et al. 2007) have been incorporated into functional response models, they are usually a function of predator density. No study we know of incorporates lag as we do here. In the present model we have assumed that the predator density is constant and high enough that both aggregation and interference are significant. Although this is a simplification, it allows us to examine the effects of spatial dynamics without making the model overly complex.

Substituting Eqs. (3) \& (4) for $C_{\mathrm{b}}$ and $H$ into the modified generalized functional response model (Eq. 2) defines the functional response as a function of lag,

$$
E=\frac{\left[\left(1-C_{\min }\right) \mathrm{e}^{-r_{C} L}+C_{\min }\right] C_{\mathrm{w}} N}{1+\left[\left(1-C_{\min }\right) \mathrm{e}^{-r_{C} L}+C_{\min }\right] C_{\mathrm{w}}\left[\left(1-H_{\min }\right) \mathrm{e}^{-r_{H} L}+H_{\min }\right] N}
$$

Model simulation: blue crabs feeding among clam patches. The Callinectes sapidus-Macoma balthica system provides an excellent test of how the opposing forces of aggregation and interference influence rates of prey consumption because they operate at different scales. We parameterized the model presented above (Eq. 5) using data from previous laboratory and field experiments. The discovery $\left(r_{\mathrm{C}}\right)$ and consumption $\left(r_{\mathrm{H}}\right)$ rate constants were based on the largest values for the detection distances (other prey patches: 10 to $15 \mathrm{~m}$; conspecifics: 4 to $5 \mathrm{~m}$; Clark et al. 1999a,b). We used values for $r_{\mathrm{C}}$ and $r_{\mathrm{H}}$ that yield asymptotes at approximately these lags $\left(r_{\mathrm{C}}=-0.17 ; r_{\mathrm{H}}=-0.50\right)$. We used the functional response of the blue crab to $M$. balthica in muddy sediment from laboratory experiments to calculate $C_{\mathrm{w}}=0.34$ at a clam density of 60 clams $\mathrm{m}^{-2}$ (Eggleston et al. 1992). We used the averaged handling time of isolated blue crabs feeding on $M$. balthica in the laboratory as our estimate of the handling time in the absence of interference: $H_{\min }=0.17 \mathrm{~d}$ (Eggleston et al. 1992). As lags increase, the probability of finding a patch decreases substantially, but is unlikely to diminish to 0 at biologically relevant distances, so we set $C_{\min }=0.10$. Thus, parameterized, the model predicts that prey will suffer the highest mortality at lags of $6.5 \mathrm{~m}$, and prey mortality rates will diminish rapidly at both shorter and longer lags (Fig. 1A). As we were uncertain of our estimate of $C_{\min }$, we examined the effect of varying $C_{\text {min }}$ from 0 to 0.3 (Fig. 1B). Maximum mortality varied from lags of $5.8 \mathrm{~m}$ at $C_{\min }=0$ to lags of $8.3 \mathrm{~m}$ at $C_{\min }=0.3$, and increasing $C_{\min }$ increased mortality rates at long lags. We designed a field experiment to quantify the effect of varying lag on prey mortality rates due to blue crab predation based on this a priori prediction.

A field test of the lag model. A field experiment was carried out in the Rhode River, a sub-estuary of the Chesapeake Bay (USA), in July and August 1994. Stations in a small embayment, Canning House Bay $\left(38^{\circ} 52^{\prime} 34^{\prime \prime} \mathrm{N}, 76^{\circ} 31^{\prime} 30^{\prime \prime} \mathrm{W}\right)$, were established at $50 \mathrm{~m}$ intervals parallel to shore, in approximately $1 \mathrm{~m}$ of water (tidal depth range: 0.75 to $1.25 \mathrm{~m}$ ). Canning House Bay has uniform sediment composed of muddy sand in shallow water ( $<1 \mathrm{~m}$ depth) and mud in deeper areas (>1 m depth). Preliminary surveys indicated low and relatively homogeneous density of Macoma balthica in the area (A. Hines unpubl. data). For each experimental run, lag treatments of $1,7,10$, or $50 \mathrm{~m}$ were randomly assigned to each station, and 2 stations were established as controls. We picked $1 \mathrm{~m}$, where interference should be intense, and $50 \mathrm{~m}$, where neither inter- 


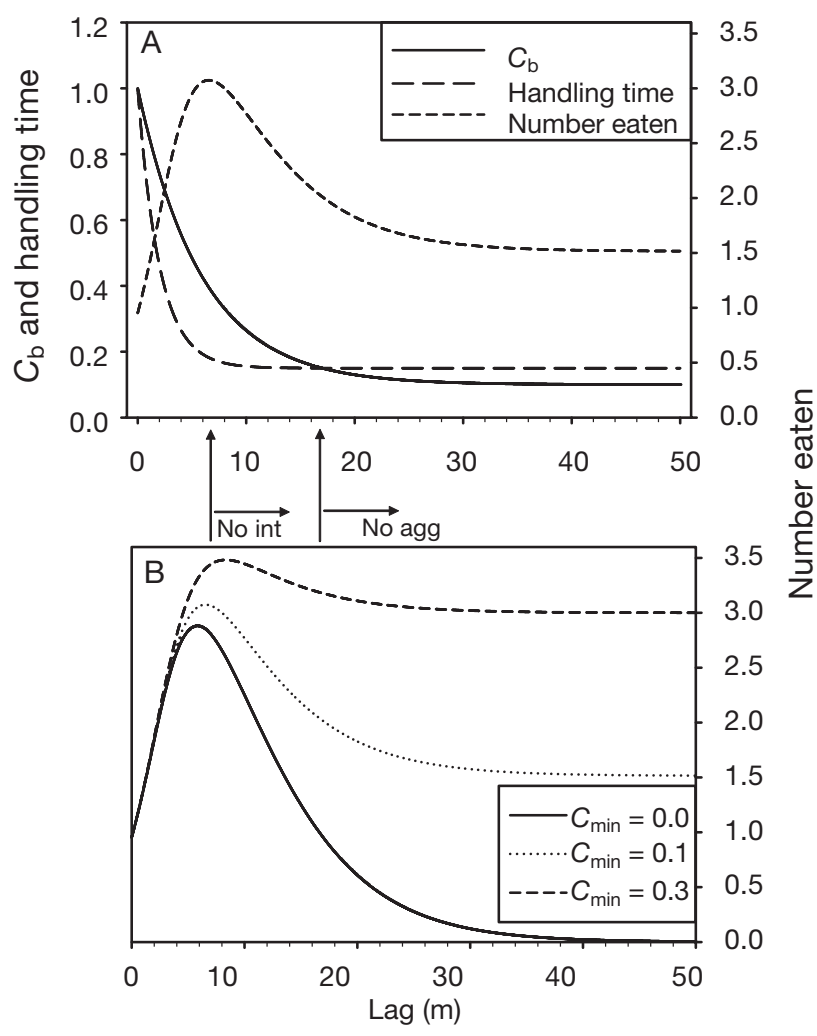

Fig. 1. Callinectes sapidus preying on Macoma balthica. (A) $C_{\mathrm{b}}$ (probability of a blue crab finding a patch), handling time, and number of clams eaten as predicted by the lag model (Eq. 5) when parameterized based on the blue crab-clam system in the Rhode River, USA: $r_{C}=0.17, r_{H}=$ $0.50, C_{\min }=0.10, H_{\min }=0.15, C_{\mathrm{w}}=0.34, \mathrm{~N}=60$. Lags at which interference (int) and aggregation (agg) become negligible are indicated with arrows. Maximal clam mortality is expected at $6.6 \mathrm{~m}$. (B) Effect of varying $C_{\min }$ from 0 to 0.3 on the model outputs. Other parameters are: $r_{C}=0.17, r_{H}=0.50$,

$$
H_{\text {min }}=0.15, C_{\mathrm{w}}=0.34, \mathrm{~N}=60
$$

ference nor aggregation should have any effect, as 2 extremes predicted by the model. We also used $7 \mathrm{~m}$, where the model predicts maximum predation rates, and $10 \mathrm{~m}$, where the model predicts intermediate predation rates. The study was unbalanced, with 4 replicates over time at 1,10 , and $50 \mathrm{~m}$, and 3 replicates at $7 \mathrm{~m}$. At each station, $0.25 \mathrm{~m}^{2}$ plots were placed at the apices of an equilateral triangle, with the length of the sides equal to the assigned lag (Fig. 2). We selected a patch size of $0.25 \mathrm{~m}^{2}$ because it is unlikely that $>1$ blue crab would forage at any given time, thus effectively eliminating intra-patch interactions (Clark et al. 1999b). The 2 control stations each had one $0.25 \mathrm{~m}^{2}$ plot. In each plot, we placed 15 marked adult $M$. balthica, creating a high-density clam patch of 60 clams $\mathrm{m}^{-2}$, which represented a significant increase over the ambient clam density in Canning House Bay, but was well within naturally occurring densities within the Rhode
River (Seitz et al. 2001). Clams, 17 to $27 \mathrm{~mm}$ shell length, were collected at nearby sites in the Rhode River, marked with an indelible marking pen, and transplanted within a $0.25 \mathrm{~m}^{2}$ frame, siphon edge up, approximately $4 \mathrm{~cm}$ below the sediment surface. Two opposite corners of each plot were marked with small floats attached with monofilament line to large nails, which were buried beneath the sediment surface to avoid any enhancement in structural complexity. Cages were then placed over each plot, and clams were given $24 \mathrm{~h}$ to acclimate and bury to natural depth. After the acclimation period, cages were removed from all lag treatment plots. The control plots remained caged. After $6 \mathrm{~h}$ exposure to predators, marked clams were recovered by placing a steel caisson over the plot and pressing it approximately 15 to $20 \mathrm{~cm}$ into the sediment. A suction sampler was then used to remove sediment, clams, and shells down to a sediment depth of $40 \mathrm{~cm}$, which is beyond the burial depth of $M$. balthica (Hines \& Comtois 1985). The samples were collected in $7 \mathrm{~mm}$ mesh bags. Marked clam recovery and unmarked (ambient) clam densities were recorded, and proportional clam mortality was calculated. The experiment was performed on 4 dates $(7,17$ July; 9, 16 August), within the seasonal peak of crab abundance in the Rhode River (Hines et al. 1990). Crabs were sampled 3 times each month from March to December using a $2 \mathrm{~m}$ wide otter trawl pulled $900 \mathrm{~m}$ at 2 stations in the Rhode River (see Hines et al. 1990 for details on trawl methods).

Statistical analysis. We analyzed ambient clam density with a 2-way analysis of variance (ANOVA) with

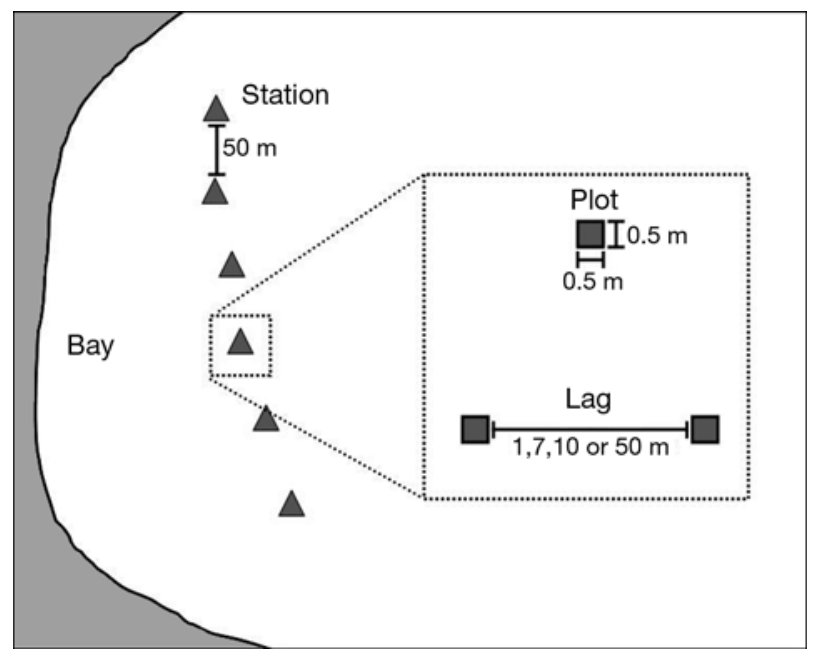

Fig. 2. Diagram of experimental design. Stations were established at $50 \mathrm{~m}$ intervals in Canning House Bay, USA ( $38^{\circ} 52^{\prime} 34^{\prime \prime} \mathrm{N}$, $\left.76^{\circ} 31^{\prime} 30^{\prime \prime} \mathrm{W}\right)$. Each station was comprised of 3 experimental plots arranged in an equilateral triangle (inset). Lag was varied by changing the length of the triangle's side at each station 

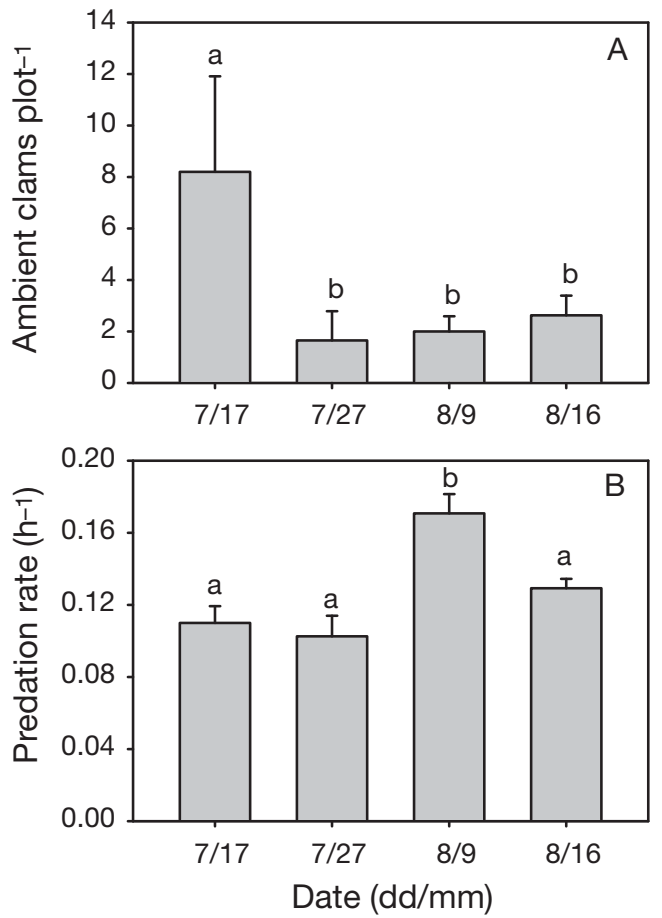

Fig. 3. Macoma balthica. (A) Mean $( \pm \mathrm{SE})$ ambient clam density and (B) mean $( \pm \mathrm{SE})$ clam mortality (square-root arcsine transformed) both averaged over the 4 dates (in 1994) of the experiment. Means with like letters are not significantly different by protected least-squares differences; $\mathrm{n}=3$ for $7 / 17$ and $\mathrm{n}=4$ for all others

date and station as factors. In this, as in all general linear model (GLM)-type analyses, we checked the assumptions of homogeneity of variance and normality and, in the cases noted, transformed the data to achieve it. To test whether the experimental results were consistent with our prediction that intermediate lags would have the highest predation rates we explored a series of GLMs and selected the best model using the Akaike's information criterion corrected for small sample size $\left(\mathrm{AIC}_{\mathrm{c}}\right)$ for each model (Burnham \& Anderson 2002). We assumed an exponential rate of loss and calculated the predation rate using:

$$
S=N \mathrm{e}^{-p t}
$$

where $S$ is the number of recovered clams, $N$ is the initial number, $p$ is the instantaneous predation rate per day, and $t$ is the time elapsed (Long \& Seitz 2008). In all models, date was included as a fixed effect. In 1 model, lag was simply considered a categorical factor; in all others, it was considered a covariate. Because our model predicts a humped shaped response (Fig. 3), we considered models that included lag $^{2}$. Additionally, because our model predicts a sharp increase in predation at low lags, with either a more gradual decrease after the peak predation rate or an approximate asymptote (depending on the $C_{\min }$ value; Fig. 3 ), we also considered models with the lag log-transformed. Ambient clam density was included in the set of models as a covariate due to its temporal and spatial variation (see 'Results'). We also considered potential interactive effects between lag and date and lag and ambient clam densities (see Table 2).

\section{RESULTS}

The retrieval rate of marked clams Macoma balthica from the caged control patches was high, $93.6 \pm 1.6 \%$ (mean \pm standard error), indicating that clam losses due to handling mortality and sampling inefficiency were negligible. Before considering the effect of experimental treatment on clam mortality, we tested for temporal and spatial patterns in the density of ambient clams; variation in density could affect predator perception of our experimental plots, and thus influence predator behavior and predation rates on experimental clams in the study area. Ambient clam density varied significantly among trial dates and among station locations throughout the study area (Table 1), and was higher on 7 July than on any other date (Fig. 3A). Thus, our experimental plots with 15 additional clams per $0.25 \mathrm{~m}^{2}$ represented a 3-fold increase in prey densities on 7 July and a 7 -fold increase on the other trial dates. There was a general trend for higher clam densities at the northern side of the bay; however, ambient clam densities did not vary among lag treatments (1-way ANOVA, $F_{3,11}=0.33, \mathrm{p}=$ 0.80 ). We controlled for the spatial and temporal variation in ambient clams by including them in some of our GLM models as a covariant.

Both lag and date affected the mortality rates of marked clams, while neither ambient clam density nor either of the interaction terms did (Table 2). Four models had an $\triangle$ AIC of $<2$ and were considered to best explain the data (Table 2). All of them included data as a factor and lag, lag and $\operatorname{lag}^{2}$, $\log (\operatorname{lag})$, or $\log (\mathrm{lag})$ and $\log (\operatorname{lag})^{2}$. In general, including $\operatorname{lag}^{2}$ and log transforming the lag values decreased the $\mathrm{AIC}_{\mathrm{c}}$. Clam predation rates increased during the course of the study, with

Table 1. ANOVA table for the effect of date and station on ambient clam Macoma balthica densities

\begin{tabular}{|lcrrrr|}
\hline Source & df & SS & MS & \multicolumn{1}{c|}{$F$} & p \\
\hline Date & 3 & 89.67 & 29.89 & 7.1 & 0.02 \\
Station & 1 & 52.20 & 52.20 & 12.4 & $<0.01$ \\
Date $\times$ Station & 3 & 49.26 & 16.42 & 3.9 & 0.06 \\
Error & 7 & 29.47 & 4.21 & & \\
\hline
\end{tabular}


Table 2. Ranking of GLMs of predation rate on clams Macoma balthica using Akaike's information criterion with small sample size correction $\left(\mathrm{AIC}_{\mathrm{c}}\right)$. Models include the factors indicated in the model column. $\mathrm{Lag}_{\mathrm{c}}$ : lag as a categorical factor; Lag: lag as a covariate; Ambient: ambient clam densities. The 4 most likely models are shown in bold font; the most likely model, presented in Fig. 5, is also underlined

\begin{tabular}{|c|c|c|c|c|c|}
\hline Model & Parameters & $\mathrm{AIC}_{\mathrm{c}}$ & $\Delta \mathrm{AIC}_{\mathrm{c}}$ & Likelihood & $\begin{array}{c}\mathrm{AIC}_{\mathrm{c}} \\
\text { weights }\end{array}$ \\
\hline $\operatorname{Lag}_{\mathrm{c}}$, Date & 8 & -50.17 & 10.00 & 0.01 & 0.00 \\
\hline Lag, Date & 6 & -59.48 & 0.69 & 0.71 & 0.21 \\
\hline Lag, Lag $^{2}$, Date & 7 & -59.51 & 0.65 & 0.72 & 0.22 \\
\hline Log(lag), Date & 6 & -59.87 & 0.30 & 0.86 & 0.26 \\
\hline $\log (\operatorname{lag}), \log (\operatorname{lag})^{2}$, Date & 7 & -60.17 & 0.00 & 1.00 & 0.30 \\
\hline$\overline{\log (\operatorname{lag}), \log (\operatorname{lag})^{2}}, \overline{\text { Date}}$, Ambient & 8 & -51.08 & 9.09 & 0.01 & 0.00 \\
\hline $\log (\operatorname{lag}), \log (\operatorname{lag})^{2}$, Date, Date $\times \log (\operatorname{lag})$ & 10 & -21.68 & 38.49 & 0.00 & 0.00 \\
\hline $\log (\operatorname{lag}), \log (\operatorname{lag})^{2}$, Date, Ambient, Ambient $\times \log (\operatorname{lag})$ & 9 & -38.05 & 22.12 & 0.00 & 0.00 \\
\hline $\log (\operatorname{lag}), \log (\operatorname{lag})^{2}$, Date, Ambient, Date $\times \log (\operatorname{lag})$, Ambient $\times \log (\operatorname{lag})$ & 12 & 82.05 & 142.21 & 0.00 & 0.00 \\
\hline
\end{tabular}

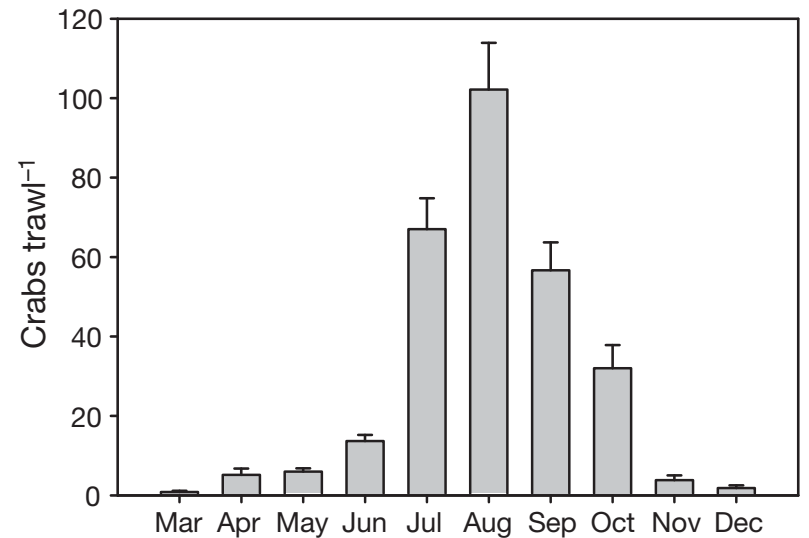

Fig. 4. Callinectes sapidus. Monthly mean $( \pm \mathrm{SE})$ blue crabs per $900 \mathrm{~m}$ trawl in the Rhode River, USA, during 1994; $\mathrm{n}=6$ for each month

highest predation rates during the August 9 sampling (Fig. 3B). The peak of blue crab Callinectes sapidus abundance in the vicinity of the experimental site coincided with our trial dates (Fig. 4). We present the GLM table for the best fitting model (Table 3 ) and show the predicted predation rates based on this model (Fig. 5). Mean predation was highest at an intermediate lag of $7 \mathrm{~m}_{i}$ percent mortality at a lag of $7 \mathrm{~m}$ was $9 \%$ higher than at $50 \mathrm{~m}$.

\section{DISCUSSION}

Experimental results supported our model-based a priori predictions about predator aggregation and interference over different inter-patch distances; highest clam Macoma balthica mortality occurred at intermediate lags (Fig. 5). The lag model predicted the peak clam mortality at a lag of $6.5 \mathrm{~m}$, and we observed
Table 3. GLM table for best fit model of clam Macoma balthica mortality including the linear and quadratic Log(lag) variables

\begin{tabular}{|lccccc|}
\hline Source & df & SS & MS & $F$ & $p$ \\
\hline Log(lag) & 1 & 0.002 & 0.002 & 6.77 & 0.029 \\
Log(lag) $^{2}$ & 1 & 0.001 & 0.001 & 6.14 & 0.035 \\
Date & 3 & 0.010 & 0.003 & 14.61 & 0.001 \\
Error & 9 & 0.002 & 0.0002 & & \\
\hline
\end{tabular}

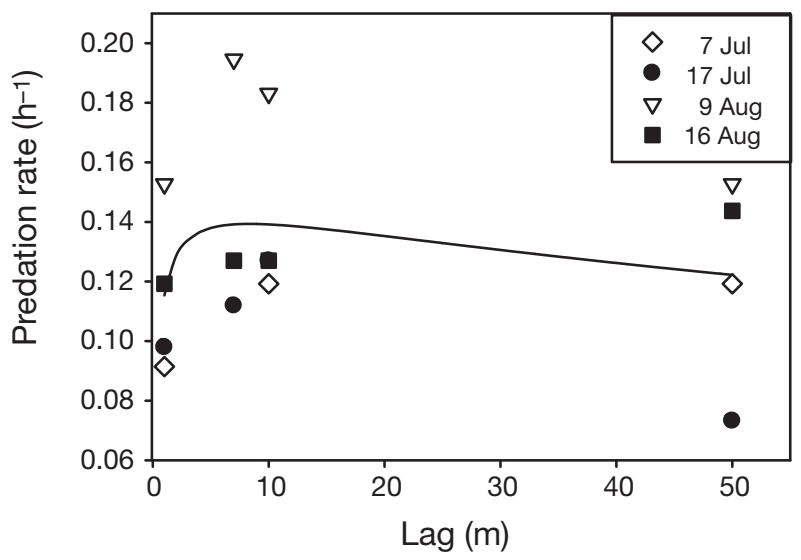

Fig. 5. Callinectes sapidus preying on Macoma balthica. Predation rates across the 4 lags with the quadratic curve fit (solid line) for each of the 4 sampling dates. Predicted clam mortality $=0.115+0.052[\log (\operatorname{lag})]-0.028[\log (\operatorname{lag})]^{2}, \mathrm{R}^{2}=0.85$ (GLM)

maximum mortality at lags of $7.0 \mathrm{~m}$, which was the closest lag tested. At lags of 7 and $10 \mathrm{~m}$, facilitation, due to the crabs' Callinectes sapidus aggregative response, likely increased feeding efficiency, while inter-patch agonistic crab interactions did not reduce feeding efficiency. We thus demonstrate that inter- 
patch distance can be an important factor in determining the predator functional response across heterogeneous seafloor landscapes. The net effect on clam densities can be substantial; in our experiment the $50 \mathrm{~m}$ lag plots had a final marked clam density that was $20 \%$ higher than that of our $7 \mathrm{~m}$ lag plots.

Both patch size and predator density likely have an interactive effect with lag on predation rates. Increasing the size of a patch most likely increases intra-patch predator aggregation and interference. Likewise, increasing predator density increases both the ability of predators to aggregate or otherwise facilitate predation (Nilsson et al. 2007) and the potential for interference among predators (Clark et al. 1999b, Skalski \& Gilliam 2001). In the present experiments we tried to minimize the intra-patch effects by keeping our patch size small enough that blue crabs were unlikely to use them simultaneously (Clark et al. 1999b). However, investigating the effects of patch size in isolation or in combination with lag should be explored in future experiments.

The discrepancy between the model prediction and the field estimate was low, given the number of factors present in the field, but not accounted for by the model. Although data relating to the maximal detection distances were used to estimate the rate constants, the shape of the response was unknown. The negative exponential function is a reasonable first approximation of the processes. The model also predicted a more pronounced difference in predation rate between the intermediate and extreme lags than we observed. This could be partially due to underestimating $C_{\min }$ or because our modeling framework and experimental approach assumed discrete patches. Prey is seldom distributed in such sharply delineated patches; prey densities are more often graded from high- to lowdensity areas. This model and conceptual framework also apply to situations where gradients exist, as is the case with Macoma balthica, but the importance of lag will decrease as the gradient between high- and lowdensity regions becomes more gradual (Seitz et al. 2008). The 'background density' of prey surrounding a patch can have significant effects on prey survival (Kuhlmann \& Hines 2005), as well as other ecological interactions (Thrush et al. 1997b, Lohrer et al. 2004). Nevertheless, it is common for larvae of benthic invertebrates to settle in distinct, often sharply defined patches that attract predators (Dubois et al. 2007, Nestlerode et al. 2007); similarly, benthic algae and seagrasses also grow in well-delineated patches that attract herbivores (Heck \& Valentine 2006).

Although we tested the predictions of our model in a crab-clam predator-prey system, the model is sufficiently general to apply it to any system where prey are patchily distributed and predators display an aggregative response or mutual interference. Alterations in the rates of decay for $C_{\mathrm{b}}$ and $H$ can be adjusted based on the mobility and behavior of the predator; as with most scaling problems, natural history information is important to determine the relevance of spatial heterogeneity of prey patches.

There are many cases in which highly mobile predators aggregate at larger scales than the scales of interference, including shorebirds feeding on infauna (Ens \& Goss-Custard 1984) and rays feeding on bivalves (Hines et al. 1997). In these systems, interference occurs at very small spatial scales, usually due to direct contact between predators as they forage, so $H$ decays quickly and $C_{\mathrm{b}}$ decays slowly. In these instances, our model predicts that the effects of lag will only be apparent when the lag < animal size. This is the case for ruddy turnstones Anenaria interpres feeding on experimental patches (Vahl et al. 2007).

The effect of these small-scale spatial and temporal processes is the relative homogenization of prey-item distribution. Over $50 \%$ of the clams transplanted in the present study were consumed by predators within $6 \mathrm{~h}$. This indicates that predators are capable of reducing the density of clams in a small high-density patch to the ambient densities within a few days. When these processes are scaled up, both spatially (to 10s of kilometers) and temporally (to months), predation on Macoma balthica homogenizes large-scale clam densities (Seitz et al. 2008). At these larger scales, bivalve density is probably driven by factors that increase (e.g. physiological stress; Long \& Seitz 2008, Long et al. 2008), or decrease (e.g. predator access; Beal 2006) predation risk independently of clam density, or by bottom-up factors (Seitz \& Lipcius 2001). A similar pattern of large-scale equalization of prey densities also occurs with shorebirds feeding on infauna (Schneider 1978).

\section{CONCLUSIONS}

One of the strengths of the present study was the use of natural history information to frame an a priori hypothesis and model. This enabled us to perform the experiment at the appropriate spatial scale, both increasing the power of the study and avoiding missing important aspects of the system (Cummings et al. 1997, Hewitt et al. 2007); had we only examined lags from 1 to $10 \mathrm{~m}$, we would have underestimated the importance of aggregation. In this system, we observed a predictable pattern of predation rate within a heterogeneous landscape of prey densities that was most likely caused by 2 predator behaviors, aggregation and interference, operating on different scales, thus highlighting the interaction between scale and ecological processes (Thrush et al. 1997a). 
Acknowledgements. We thank S. Godwin, J. Merritt, and members of the SERC Crablab for field assistance. J. Hewitt, D. Lohrer, and R. Lipcius provided helpful suggestions and discussion. We are grateful to K. Tenore, V. Kennedy, J. Long and 3 anonymous reviewers for critical comments, and to E. Russek-Cohen for statistical advice. The work was funded by grants from the Smithsonian Environmental Sciences program to A.H.H.; NSF Grant OCE9000483 to A.H.H., R. Lipcius, and T. Wolcott; Disney Wildlife Conservation fund to A.H.H. and T. Wolcott; Smithsonian Visiting Scientist Award to S.F.T.; NSF RTG grant to A.H.H. and others. W.C.L. was supported by a Marine Science Network Fellowship from the Smithsonian. S.F.T. thanks the researchers at SERC for their hospitality and friendship.

\section{LITERATURE CITED}

Beal BF (2006) Relative importance of predation and intraspecific competition in regulating growth and survival of juveniles of the soft-shell clam, Mya arenaria L., at several spatial scales. J Exp Mar Biol Ecol 336:1-17

Burnham KP, Anderson DR (2002) Model selection and multimodel inference: a practical information-theoretic approach, 2nd edn. Springer Science, New York

Clark ME, Wolcott TG, Wolcott DL, Hines AH (1999a) Foraging and agonistic activity co-occur in free-ranging blue crabs Callinectes sapidus: observation of animals by ultrasonic telemetry. J Exp Mar Biol Ecol 233:143-160

> Clark ME, Wolcott TG, Wolcott DL, Hines AH (1999b) Intraspecific interference among foraging blue crabs Callinectes sapidus: interactive effects of predator density and prey patch distribution. Mar Ecol Prog Ser 178:69-78

Clark ME, Wolcott TG, Wolcott DL, Hines AH (2000) Foraging behavior of an estuarine predator, the blue crab Callinectes sapidus in a patchy environment. Ecography 23: $21-31$

Cummings VJ, Schneider DC, Wilkinson MR (1997) Multiscale experimental analysis of aggregative responses of mobile predators to infaunal prey. J Exp Mar Biol Ecol 216: 211-227

Dubois S, Comtet T, Retière C, Thiébaut E (2007) Distribution and retention of Sabellaria alveolata larvae (Polychaeta: Sabellariidae) in the Bay of Mont-Saint-Michel, France. Mar Ecol Prog Ser 346:243-254

Eggleston DB, Lipcius RM, Hines AH (1992) Density-dependent predation by blue crabs upon infaunal clam species with contrasting distribution and abundance patterns. Mar Ecol Prog Ser 85:55-68

Ens BJ, Goss-Custard JD (1984) Interference among oystercatchers, Haematopus ostralegus feeding on mussels, $M y-$ tilus edulis, on the Exe Estuary. J Anim Ecol 53:217-231

Goss-Custard JD (1980) Competition for food and interference among waders. Ardea 68:31-52

Hassell MP (1978) Arthropod predator-prey systems. Princeton University Press, Princeton, NJ

> Heck KL Jr, Valentine JF (2006) Plant-herbivore interactions in seagrass meadows. J Exp Mar Biol Ecol 330:420-436

> Hewitt JE, Thrush SF, Dayton FK, Bonsdorff E (2007) The effect of spatial and temporal heterogeneity on the design and analysis of empirical studies of scale-dependent systems. Am Nat 169:398-408

Hines AH, Comtois KL (1985) Vertical distribution of infauna in sediments of a subestuary of central Chesapeake Bay. Estuaries 8:296-304

> Hines AH, Haddon AM, Wiechert LA (1990) Guild structure and foraging impact of blue crabs and epibenthic fish in a subestuary of Chesapeake Bay. Mar Ecol Prog Ser 67: 105-126

Hines $\mathrm{AH}$, Whitlatch RB, Thrush SF, Hewitt JE, Cummings VJ, Dayton PK, Legendre P (1997) Nonlinear foraging response of a large marine predator to benthic prey: eagle ray pits and bivalves in New Zealand sandflats. J Exp Mar Biol Ecol 216:191-210

Holling CS (1959) The components of predation as revealed by a study of small mammal predation of the European pine sawfly. Can Entomol 91:293-320

> Jachowski RL (1974) Agonistic behavior of the blue crab, Callinectes sapidus Rathbun. Behaviour 50:232-253

Krebs CJ (1985) Ecology: the experimental analysis of distribution and abundance. Harper and Row, New York

> Kuhlmann ML, Hines AH (2005) Density-dependent predation by blue crabs Callinectes sapidus on natural prey populations of infaunal bivalves. Mar Ecol Prog Ser 295: 215-228

Lohrer AM, Thrush SF, Hewitt JE, Berkenbusch K, Ahrens M, Cummings VJ (2004) Terrestrially derived sediment: response of marine macrobenthic communities to thin terrigenous deposits. Mar Ecol Prog Ser 273:121-138

> Long WC, Seitz RD (2008) Trophic interactions under stress: hypoxia enhances foraging in an estuarine food web. Mar Ecol Prog Ser 362:59-68

Long WC, Brylawski BJ, Seitz RD (2008) Behavioral effects of low dissolved oxygen on the bivalve Macoma balthica. J Exp Mar Biol Ecol 359:34-39

> Mansour RA, Lipcius RM (1991) Density-dependent foraging and mutual interference in blue crabs preying upon infaunal clams. Mar Ecol Prog Ser 72:239-246

> Master TL, Frankel M, Russell M (1993) Benefits of foraging in mixed-species wader aggregations in a southern New Jersey saltmarsh. Colon Waterbirds 16:149-157

Nachman G (2006) The effects of prey patchiness, predator aggregation, and mutual interference on the functional response of Phytoseiulus persimilis feeding on Tetranychus urticae (Acari: Phytoseiidae, Tetranychidae). Exp Appl Acarol 38:87-111

> Nestlerode JA, Luckenbach MW, O'Beirn FX (2007) Settlement and survival of the oyster Crassostrea virginica on created oyster reef habitats in Chesapeake Bay. Restor Ecol 15:273-283

Nilsson PA, Lundberg P, Brönmark C, Persson A, Turesson H (2007) Behavioral interference and facilitation in the foraging cycle shape the functional response. Behav Ecol 18: 354-357

> Schneider DC (1978) Equalization of prey numbers of migratory shorebirds. Nature 271:353-354

Schneider DC (1982) Fronts and seabird aggregations in the southeastern Bering Sea. Mar Ecol Prog Ser 10:101-103

> Schneider DC (1992) Thinning and clearing of prey by predators. Am Nat 139:148-160

> Schwinning S, Rosenweig ML (1990) Periodic oscillations in an ideal-free predator-prey distribution. Oikos 59: 85-91

Seitz RD, Lipcius RN (2001) Variation in top-down and bottom-up control of marine bivalves at differing spatial scales. ICES J Mar Sci 58:689-699

Seitz RD, Lipcius RN, Hines AH, Eggleston DB (2001) Density-dependent predation, habitat variation, and the persistence of marine bivalve prey. Ecology 82:2435-2451

Seitz RD, Lipcius RN, Knick KE, Seebo MS, Long WC, Brylawski BJ, Smith A (2008) Stock enhancement and carrying capacity of blue crab nursery habitats in Chesapeake Bay. Rev Fish Sci 16:329-337

Skalski GT, Gilliam JF (2001) Functional responses with pre- 
dator interference: viable alternatives to the Holling type II model. Ecology 82:3083-3092

Smallegange IM, van der Meer J, Kurvers RHJM (2006) Disentangling interference competition from exploitative competition in a crab-bivalve system using a novel experimental approach. Oikos 113:157-167

Smith LD (1995) Effects of limb autotomy and tethering on juvenile blue crab survival from cannibalism. Mar Ecol Prog Ser 116:65-74

Smith IP, Taylor AC (1993) The energetic cost of agonistic behavior in the velvet swimming crab, Necora puber (L.). Anim Behav 45:375-391

Thrush SF, Pridmore RD, Hewitt JE, Cummings VJ (1994) The importance of predators on a sandflat: interplay between seasonal changes in prey densities and predator effects. Mar Ecol Prog Ser 107:211-222

Thrush SF, Pridmore RD, Bell RG, Cummings VJ and others (1997a) The sandflat habitat: scaling from experiments to conclusions. J Exp Mar Biol Ecol 216:1-9

Editorial responsibility: Thomas Minello,

Galveston, Texas, USA
Thrush SF, Cummings VJ, Dayton PK, Ford R and others (1997b) Matching the outcome of small-scale density manipulation experiments with larger scale patterns: an example of bivalve adult/juvenile interactions. J Exp Mar Biol Ecol 216:153-170

- Turchin P, Kareiva P (1989) Aggregation in Aphis varians: an effective strategy for reducing predation risk. Ecology 70 : 1008-1016

> Vahl WK, van der Meer J, Meijer K, Piersma T, Veissing FJ (2007) Interference competition, the spatial distribution of food and free-living foragers. Anim Behav 74:1493-1503

Weissburg M, Zimmer-Faust RK (1993) Life and death in moving fluids: Hydrodynamic effects on chemosensory-mediated predation. Ecology 74:1428-1443

Wiens JA (1989) Spatial scaling in ecology. Funct Ecol 3: 385-397

Zimmer-Faust RK, Commins JE, Browne KA (1999) Regulatory effects of environmental chemical signals on search behaviour and foraging success. Ecology 80:1432-1446

Submitted: March 25, 2008; Accepted: April 9, 2009

Proofs received from author(s): June 8, 2009 